\title{
Bağlarbaşı-Tekke (Gümüşhane) Karayolundaki Kaya Şevlerinin Kinematik ve Limit Denge Yöntemleri İle Değerlendirilmesi
}

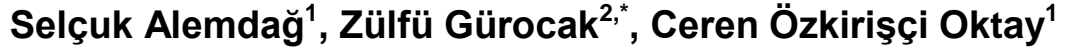 \\ ${ }^{1}$ Gümüşhane Üniversitesi, Mühendislik Fakültesi, Jeoloji Mühendisliği Bölümü, 29000, Gümüşhane. \\ ${ }^{2}$ Fırat Üniversitesi, Mühendislik Fakültesi, Jeoloji Mühendisliği Bölümü, 23119, Elazığ.
}

\section{Özet}

Kinematik analiz yöntemi, kaya sevlerinde düzlemsel, kama ve devrilme gibi yenilmeleri değerlendirmek için yaygın olarak kullanılan analiz yöntemlerinden birisidir. Bu yöntemde, olası yenilme tiplerini belirlemek için şev ve süreksizliklerin yönelimleri ile süreksizliklerin içsel sürtünme açıları kullanılır. Ancak, kinematik analizlerden elde edilen sonuçların güvenirliği optimum şev tasarımı için yeterli değildir. Bu nedenle, kinematik analiz sonuçlarının limit denge analizleri veya sayısal analizler ile kontrol edilmesi gereklidir. Bu çalışmada, Bağlarbaşı-Tekke (Gümüşhane) karayolundaki kaya şevlerinin duraylıliğı kinematik ve limit denge analizleri ile incelenmiştir. Kinematik analiz sonuçlarl, (5), (6) ve (7) nolu kaya şevlerinde düzlemsel ve kama tipi duraysızlıkların ortaya çıkabileceğini göstermektedir. Düzlemsel ve kama türü için yapılan limit denge analizleri, (5) ve (6) nolu şevlerin duraysız iken (7) nolu şevin ise duraylı olduğunu göstermektedir.

Anahtar Sözcükler

Gümüşhane, Kaya Şevi, Kinematik Analiz, Limit Denge Analizi

\section{Assessment of the Rock Slopes by Kinematic and Limit Equilibrium Methods on the Bağlarbaşı-Tekke (Gümüşhane) Motorway}

\begin{abstract}
Kinematic analysis method is one of the widely used methods to evaluate potential failures such as planar, wedge and toppling in rock slopes. In this method, orientations of slope and discontinuity with the friction angle of the discontinuities planes are used to analyze possible failure types. However, the reliability of the results obtained from kinematical analyses is not sufficient for optimum slope design. For this reason, it is necessary that the results of kinematical analyses should be controlled using limit equilibrium or numerical analyses. In this study, stability of rock slopes on the highway of Bağlarbaşı-Tekke (Gümüşhane) was investigated using kinematical and limit equilibrium analyses. The results of the kinematical analyses showed that there may be planar and wedge type instabilities for the rock slopes numbered 5, 6, and 7. The limit equilibrium analyses conducted for the types of plane and wedge show that the rock slopes numbered 5 and 6 are instable while number 7 is stable.
\end{abstract}

$\underline{\text { Keywords }}$

Gümüşhane, Rock Slope, Kinematic Analysis, Limit Equilibrium Analysis

\section{Giriş}

Dünya'da meydana gelen doğal afetler içerisinde kitle hareketleri en yaygın olarak görülenlerden birisidir ve çoğu zaman önemli ekonomik kayıplarla birlikte can kayıplarına da neden olmaktadırlar. Türkiye için de benzer durum söz konusudur ve özellikle Doğu Karadeniz Bölgesi bu anlamda önemli risk alanlarından birisini oluşturmaktadır. Bu bölgede meydana gelen kitle hareketleri incelendiğinde en etkili sebeplerin Trabzon ve Rize illeri için aşırı yağışlar, yüksek topoğrafik eğim, akarsu aşındırmaları ve mühendislik projelerinin yapımında uygulanan yanlış kazı çalışmaları olduğu görülmektedir. Gümüşhane İli ve yakın çevresinde ise yüksek topoğrafik eğim, kayaçların aşırı derecede eklemli ve ayrışmış olması, mühendislik projelerinin yapılmasında uygulanan yanlış kazı ve patlatmaların şevlerde kazı sırasında veya kazı sonrasında duraysızlıklara neden olduğu görülmektedir. Bu duraysızlıkları önlemek için tasarım öncesi gerçekleştirilmesi gereken jeoteknik çalışmaların mevcut durumu en iyi şekilde ortaya koyacak şekilde yapılması ve tasarım sırasında uygun şev analiz yöntemlerinin kullanılması önem taşımaktadır.

Bu çalışmada, Doğu Karadeniz'i Doğu Anadolu’ya bağlayan tarihi İpek Yolu güzergahında Gümüşhane İli’ne bağlı Bağlarbaş1-Tekke (Şekil 1) yerleşim alanları arasındaki karayolu çalışmaları sırasından oluşturulan şevlerin duraylılığı kinematik ve limit denge analiz yöntemleri ile araştırılmış, meydana gelebilecek duraysızlıkları önlemek amacıyla güvenli şev yönelimleri belirlenmiştir. Yapılan çalışmalar arazi, laboratuvar ve duraylılık analiz çalışmaları olmak üzere üç aşamada gerçekleştirilmiştir. Arazi çalışmaları sırasında çalışma alanının jeoloji haritası hazırlanmış, karayolu 
güzergahındaki yedi adet kaya şevinde süreksizlik özelliklerinin belirlenebilmesi için hat etütleri yapılmış ve laboratuvar deneylerinde kullanılmak üzere blok örnekler derlenmiştir. Laboratuvar çalışmaları ile kaya malzemesinin fiziksel ve mekanik özellikleri ile süreksizliklerin dayanım parametreleri belirlenmiştir. Arazi ve laboratuvar çalışmalarından elde edilen veriler yardımıyla kaya şevlerinin duraylılığı kinematik ve limit denge analizi yöntemleri kullanılarak değerlendirilmiş, duraysızlıkların belirlendiği şevler için duraylı şev yönelimleri belirlenmeye çalışılmıştır.

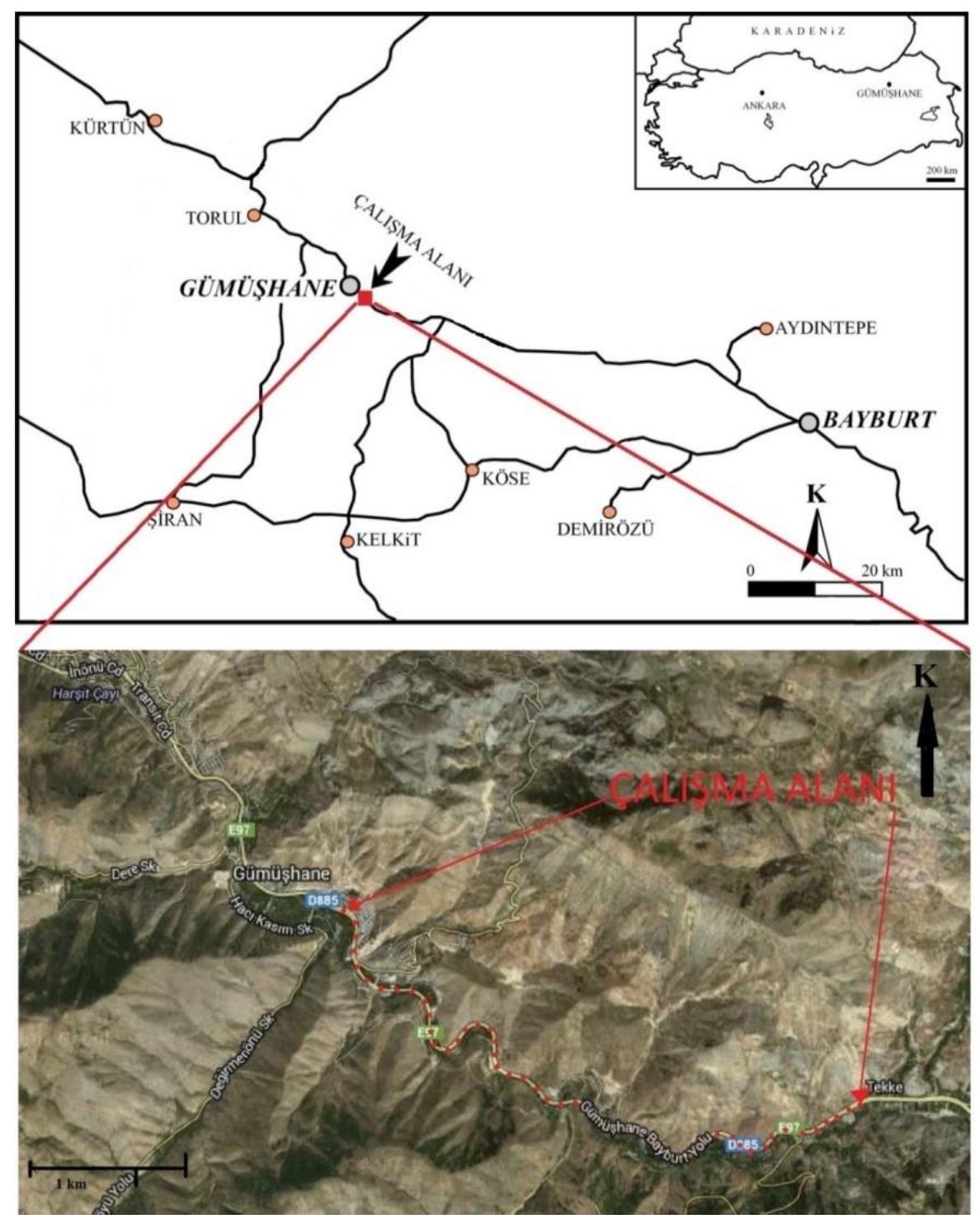

Şekil 1: Çalışma alanına ait yer bulduru haritası

\section{2. Çalışma Alanının Jeolojisi}

İnceleme alanı Pontid Tektonik Birliği'nin (Ketin 1966) doğusunda ve Doğu Pontid Güney Zonu'nda (Gedikoğlu vd. 1979) yer almaktadır. Bölgede yüzeyleme veren birimleri yaşlıdan gence doğru granit, granodiyorit ve monzogranit gibi derinlik kayaçları ile temsil edilen Orta-Geç Karbonifer yaşlı Gümüşhane Granitoyidleri, tabanda kırmızı kireçtaşları ile başlayan ve tüfit arakatkılı kiltaşı, kumtaşı, marn ardalanması ile devam eden Erken-Orta Jura yaşlı Şenköy Formasyonu, dolomitik ve mikritik kireçtaşı litolojisinden oluşan Jura-Erken Kretase yaşlı Berdiga Formasyonu, tüfit ara katkılı gri renkli, kumtaşı, silttaşı ve marn ardalanmasından oluşan Geç Kretase yaşlı Kermutdere Formasyonu ve çimentolanmamış, iyi yuvarlaklaşmış, blok, çakıl, kum ve kil boyutundaki elemanlardan oluşan Kuvaterner yaşlı alüvyonlar şeklinde sıralamak mümkündür (Şekil 2). Bu çalışmaya konu olan kaya şevleri Gümüşhane Granitoyidleri içerisinde yer almaktadır. Birim, Yılmaz (1972) tarafından Gümüşhane Granitoyidi olarak adlandırılmış ve ayrıntılı bir şekilde incelenmiştir. Gümüşhane Granitoyidleri üst seviyelerde tamamen ayrışmış olup, yoğun eklemler içermektedir. Eklemli yapısı, iri kristalleri, pembemsi rengi ve altere olmuş görünümleriyle arazide diğer birimlerden kolaylıkla ayırt edilmektedir (Özkirişçi Oktay 2014). 


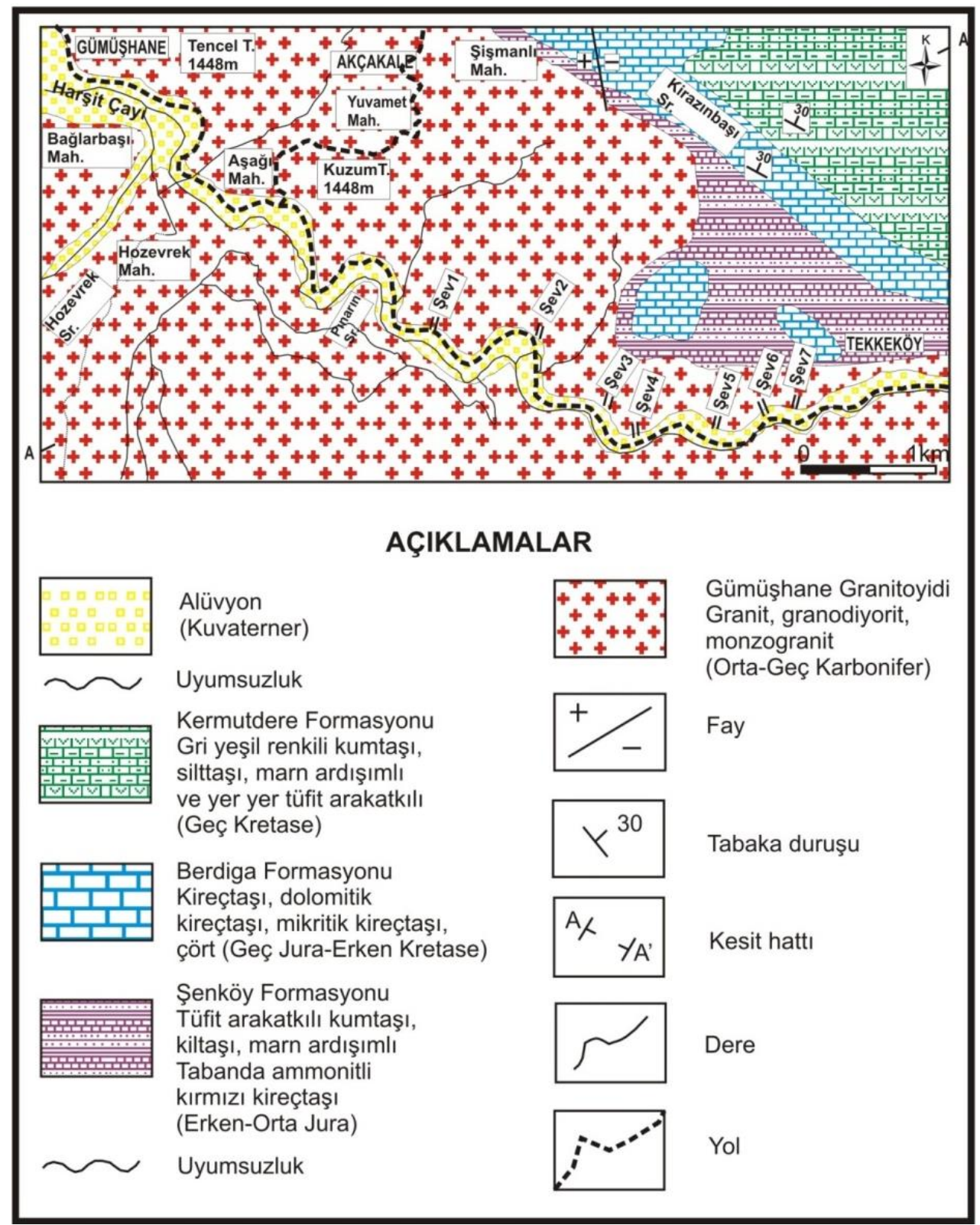

Şekil 2: Çalışma alanının jeoloji haritası (Özkirişçi Oktay 2014)

\section{Arazi ve Laboratuvar Çalışmaları}

$\mathrm{Bu}$ çalışmada, Bağlarbaşı-Tekke (Gümüşhane) arasındaki yedi adet kaya şevinin duraylılığını incelemek amacıyla gerçekleştirilen jeoteknik çalışmalar kapsamında süreksizliklerin mühendislik ve makaslama dayanımı özelliklerini belirlemek amacıyla arazi ve laboratuvar çalışmaları gerçekleştirilmiştir.

Süreksizliklerin mühendislik özellikleriyle ilgili veri toplanmasında istatistiksel anlamda en tatmin edici sonuçların alındığı yöntem, hat etüdü yöntemidir. Jenning (1970) tarafindan önerilen yöntem, daha sonra Piteau (1970) tarafından revize edilmiş, Fookes ve Denness (1969), Attewel ve Farmer (1976), Priest ve Hudson (1981) gibi araştırmacılar ile ISRM (1978) tarafından geliştirilmiştir ve sonraki yıllarda ISRM (2007) tarafindan yapılan önerilerle bugünkü halini almıştır. Arazi çalışmaları sırasında Gümüşhane Granitoyidi’nin içerdiği eklemlerin aralık, açıklık, devamlılık, pürüzlülük, dolgu, ayrışma ve su durumunu belirlemek için hat etütleri yapılmış ve elde edilen veriler istatistiksel olarak değerlendirilerek ortalama değerler Tablo 1'de sunulmuştur

Eklem yönelimlerini belirlemek amacıyla her bir kaya şevinden yönelim ölçüleri alınmış ve bu yönelim değerleri Dips v5.1 programı (Rocscience 2002) ile değerlendirilerek kontur diyagramları çizilmiş (Şekil 3) ve Gümüşhane Granitoyidi’nin içerdiği eklemlere ait ana yönelimler belirlenmiştir. Yapılan değerlendirmeler sonucunda elde edilen eklem ana yönelimleri Tablo 2'de verilmiştir. 
Tablo 1: Eklemlerin mühendislik özelliklerine ait ortalama değerler

\begin{tabular}{|l|c|c|c|c|c|c|c|}
\hline \multirow{2}{*}{$\begin{array}{l}\text { Mühendislik } \\
\text { Özelliği }\end{array}$} & \multicolumn{7}{|c|}{ Şevler } \\
\cline { 2 - 8 } & $\mathbf{1}$ & $\mathbf{2}$ & $\mathbf{3}$ & $\mathbf{4}$ & $\mathbf{5}$ & $\mathbf{6}$ & $\mathbf{7}$ \\
\hline Aralık (mm) & 131.26 & 173.82 & 85.29 & 134.85 & 59.00 & 128.99 & 60.25 \\
\hline Açıklık (mm) & 8.22 & 9.47 & 5.87 & 4.91 & 2.82 & 4.68 & 12.07 \\
\hline Devamlılık (m) & 0.42 & 0.80 & 0.64 & 0.60 & 0.73 & 0.37 & 0.27 \\
\hline Pürüzlülük (JCR) & 13.20 & 12.10 & 8.51 & 7.55 & 8.00 & 7.13 & 12.10 \\
\hline Dolgu & $\begin{array}{c}2 \mathrm{~mm} \\
\text { kil }\end{array}$ & $\begin{array}{c}2 \mathrm{~mm} \\
\text { kil }\end{array}$ & $\begin{array}{c}4 \mathrm{~mm} \\
\text { kil }\end{array}$ & $\begin{array}{c}4 \mathrm{~mm} \\
\text { kalsit }\end{array}$ & $\begin{array}{c}4 \mathrm{~mm} \\
\text { kil }\end{array}$ & $\begin{array}{c}4 \mathrm{~mm} \\
\text { kil }\end{array}$ & $\begin{array}{c}5 \mathrm{~mm} \\
\text { kil }\end{array}$ \\
\hline Bozunma & Fazla & Fazla & Fazla & Fazla & Fazla & Fazla & Fazla \\
\hline Su durumu & Kuru & Kuru & Kuru & Kuru & Kuru & Kuru & Kuru \\
\hline
\end{tabular}

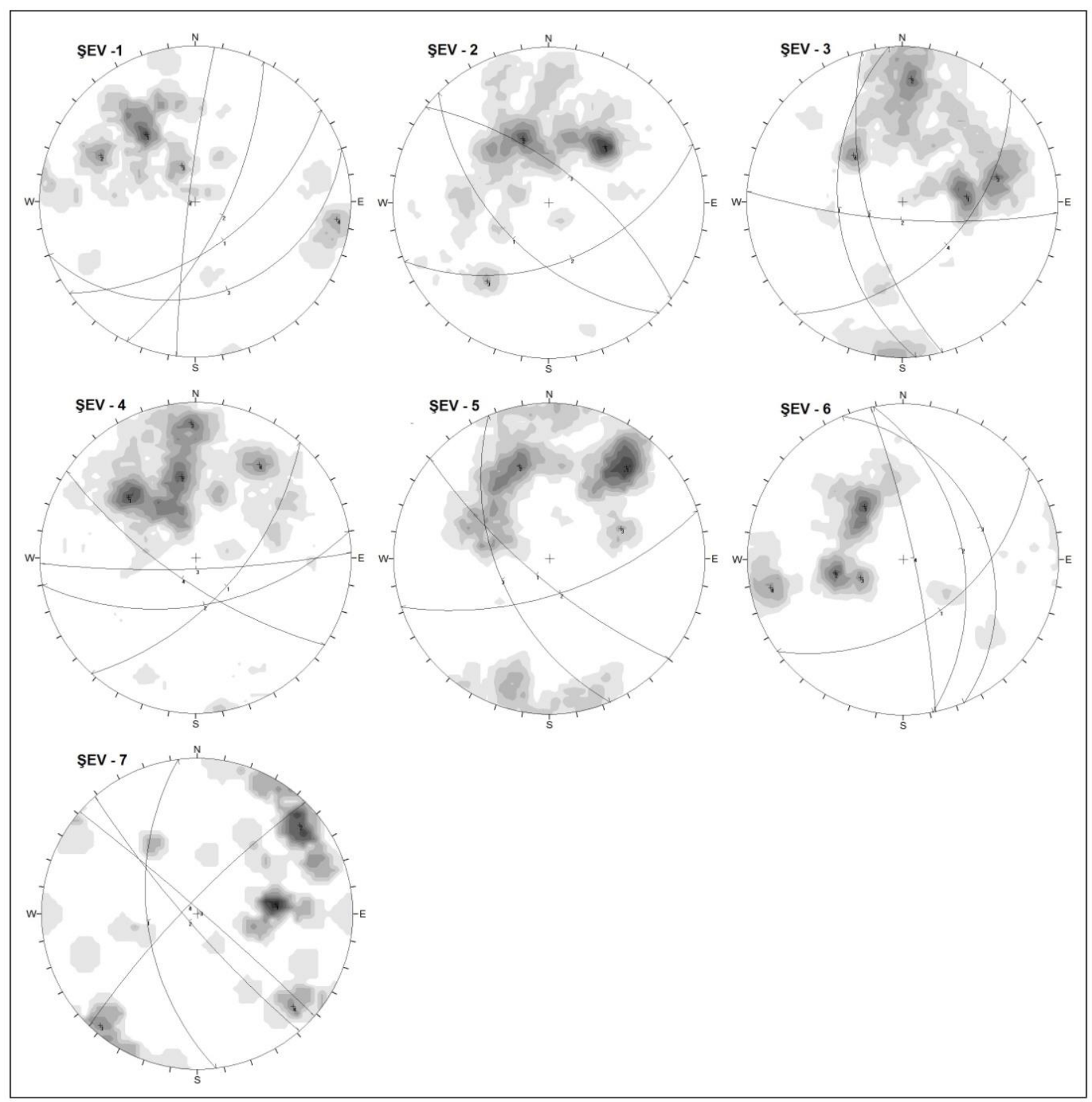

Şekil 3: Eklemlere ait kontur diyagramları 
Tablo 2: Eklemlere ait ana yönelimler

\begin{tabular}{|c|c|c|c|c|c|c|c|}
\hline \multirow{2}{*}{$\begin{array}{l}\text { Eklem } \\
\text { Setleri }\end{array}$} & \multicolumn{7}{|c|}{ Şevler } \\
\hline & 1 & 2 & 3 & 4 & 5 & 6 & 7 \\
\hline Set-1 & $147 / 65$ & $156 / 46$ & $135 / 48$ & $214 / 70$ & $216 / 72$ & $308 / 39$ & $233 / 80$ \\
\hline Set-2 & $116 / 68$ & $214 / 52$ & $182 / 75$ & $177 / 78$ & $138 / 55$ & $140 / 44$ & $264 / 53$ \\
\hline Set-3 & $152 / 26$ & $38 / 64$ & $259 / 58$ & $164 / 48$ & $16 / 79$ & $75 / 43$ & $312 / 80$ \\
\hline Set-4 & $282 / 82$ & - & $3 / 87$ & $134 / 59$ & - & $78 / 81$ & $39 / 84$ \\
\hline
\end{tabular}

Yapılan değerlendirmelere göre, Gümüşhane Granitoyidleri genel olarak 4 ana eklem seti ve gelișigüzel yönelime sahip eklemler içermektedir. Bu eklemler yakın ara uzaklıklı, orta derecede geniş, çok düşük devamlı, pürüzlü, genellikle 2-5 mm aralığında kil dolgu içeren, orta-fazla bozunmuş ve kuru özelliktedir.

Süreksizliklerin makaslama dayanımını ifade eden kohezyon ve içsel sürtünme açısı şev duraylılık analizlerinde kullanılan en önemli parametrelerdir. Bu çalışmada eklem setlerine ait içsel sürtünme açılarının $(\phi)$ belirlenebilmesi için arazi çalışmaları sırasında derlenen blok örnekler kullanılarak CANMET (1977) tarafından önerilen yönteme göre deformasyon kontrollü doğrudan makaslama deneyleri yapılmış ve Barton ve Choubey (1977) görgül yenilme ölçütü kullanılmıştır.

Barton ve Choubey (1977) makaslama gerilmesi ile normal gerilme arasındaki ilişkiyi;

$$
\tau=\sigma_{n} \tan \left[J R C \log \left(\frac{J C S}{\sigma_{n}}\right)+\phi_{r}\right]
$$

eşitliği ile ifade etmektedir. Bu eşitlikte;

$\tau:$ Makaslama gerilmesi,

$\sigma_{\mathrm{n}}$ : Süreksizlik düzlemine etki eden normal gerilme,

JRC : Süreksizlik pürüzlülük katsayısı,

JCS : Süreksizlik yüzeyinin dayanımı,

$\phi_{\mathrm{r}}:$ Rezidüel sürtünme açısı,

$\phi_{\mathrm{b}}$ : Süreksizliklerin temel sürtünme açısı,

$\gamma$ : Birim hacim ağırlığı ve

$\phi$ : İçsel sürtünme açısıdır.

Temel sürtünme açısını belirlemek için, blok örnekler 6x6x1cm ebatlarında kesilmiş, yüzeyleri pürüzsüz ve deneye uygun hale getirilmiş örneklerde farklı normal gerilmeler altında üç adet makaslama deneyi geçekleştirilmiştir. Bu deneylere ait normal gerilme $(\sigma)$ - kesme gerilmesi $(\tau)$ grafikleri çizilerek granit örneklerine ait temel sürtünme açısı $\left(\phi_{\mathrm{b}}\right)$ belirlenmiştir. Rezidüel sürtünme açısı ise aşağıdaki eşitlik yardımıyla belirlenmiştir.

$$
\phi_{\mathrm{r}}=\left(\phi_{\mathrm{b}}-20\right)+20(\mathrm{r}+\mathrm{R})
$$

R: Taze yüzeyin Schmidt geri sıçrama sertlik değeri

r: Bozunmuş yüzeyin Schmidt geri sıçrama sertlik değeri

Barton (1973) Görgül Yenilme Ölçütü'nde kullanılan parametrelerden süreksizlik pürüzlülük katsayısı (JRC), arazi çalışmaları sırasında eklem yüzeylerinden alınan pürüzlülük profillerinin Barton ve Choubey (1977) tarafından önerilen standart pürüzlülük profilleri ile deneştirilmesi sonucunda belirlenmiştir. JCS’nin belirlenmesinde Hoek ve Bray (1977) tarafından önerilen abak yardımıyla Schmidt geri sıçrama sertlik değeri ve kaya malzemesinin ortalama birim hacim ağırlığı değerleri kullanılmıştır. Elde edilen veriler Rocdata bilgisayar programında (Rocscience 2004) değerlendirilerek eklemlerin içsel sürtünme açıları belirlenmiştir (Tablo 3). 
Tablo 3: Eklemlerin içsel sürtünme açılarının belirlenmesinde kullanılan parametreler ve içsel sürtünme açısı değerleri

\begin{tabular}{|c|c|c|c|c|c|c|c|c|c|}
\hline $\begin{array}{l}\text { Şev } \\
\text { No }\end{array}$ & $\begin{array}{c}\text { Şev } \\
\text { Yüksekliği } \\
\text { (m) }\end{array}$ & $\begin{array}{l}\phi_{\mathrm{b}} \\
\left(^{\circ}\right)\end{array}$ & $\begin{array}{l}\phi_{\mathbf{r}} \\
\left(^{\circ}\right)\end{array}$ & $\begin{array}{c}\text { JCS } \\
(\mathbf{M P a})\end{array}$ & JRC & $\mathbf{r}$ & $\mathbf{R}$ & $\begin{array}{c}\gamma \\
\left(k N / m^{3}\right)\end{array}$ & $\begin{array}{l}\phi \\
\left(^{\circ}\right)\end{array}$ \\
\hline 1 & 20 & 37 & 30 & 37 & 13.2 & 39 & 62 & 24.71 & 49 \\
\hline 2 & 12 & 36 & 29 & 34 & 12.1 & 28 & 43 & 25.30 & 49 \\
\hline 3 & 25 & 31 & 29 & 90 & 8.5 & 49 & 55 & 26.38 & 45 \\
\hline 4 & 25 & 49 & 48 & 43 & 7.5 & 40 & 58 & 26.09 & 59 \\
\hline 5 & 15 & 35 & 29 & 55 & 8.0 & 44 & 63 & 25.30 & 44 \\
\hline 6 & 22 & 31 & 27 & 57 & 7.13 & 47 & 57 & 24.50 & 39 \\
\hline 7 & 15 & 30 & 25 & 58 & 12.1 & 46 & 60 & 24.60 & 47 \\
\hline
\end{tabular}

\section{Duraylılık Analizleri}

Jeoteknik, madencilik, inşaat, gibi birçok mühendislik çalışmasında duraylılık analizleri çalışmanın emniyeti ve maliyeti açısından büyük öneme sahiptir ve bu tür çalışmalarda rutin olarak yapılmaktadır. Bu duraylılık analizlerinin ana amaçlarını kaya şev duraylılık şartlarını belirlemek, potansiyel yenilme mekanizmasını araştırmak, şevlerin duraylılığına etki eden faktörleri belirlemek, optimum ve güvenli şev tasarımı yapmak, farklı destek- iyileştirme yöntemlerini belirlemek ve test etmek şeklinde sıralamak mümkündür. Kaya şevlerinin duraylılığının değerlendirilmesinde kinematik analiz, limit denge yöntemi ve sayısal analizler gibi farklı yöntemler kullanılmaktadır. Ancak, kullanılacak analiz yönteminin seçiminde potansiyel yenilme tipi, arazi şartları, tercih edilen yöntemin zayıf ve güçlü yanlarının dikkate alınması gereklidir.

Bu çalışmada, Bağlarbaşı-Tekke karayolu güzergahında Gümüşhane Granitoyidi içerisinde kesilmiş olan kaya şevlerinde süreksizliklere bağlı olarak meydana gelebilecek yenilme türlerini ve güvenli şev yönelimlerini belirlemek için kinematik ve limit denge analiz yöntemleri kullanılarak duraylılık analizleri yapılmıştır

\subsection{Kinematik Analizler}

Kaya şevlerinde meydana gelen yenilmeler dikkate alındığında, yenilemelerin genel olarak kaya kütlesinin içerdiği ve süreksizlik olarak tanımlanan eklem, tabakalanma, fay, makaslama çatlakları gibi yapısal unsurlara bağlı olarak geliştiği görülür. Süreksizliklerin kontrol ettiği bu duraysızlıkların analiz edilmesinde yaygın bir şekilde tercih edilen yöntem, kinematik analiz yöntemidir. Bu yöntem, birçok araştırmacı (Gökçeoğlu vd. 2000; Yoon vd. 2002; Kentli ve Topal 2004; Gürocak vd. 2008; Yılmaz vd. 2012; Tüdeş vd. 2012; Alemdağ vd. 2014) tarafindan en fazla tercih edilen yöntem olmasına ve birçok avantaj sunmasına karşın, bazı sınırlamalara da sahiptir.

Basit kullanımı, analizde kullanılan parametrelerin kolay belirlenebilir olması, yenilme potansiyeli hakkında ön fikir vermesi, limit denge analizleri ile bağlantılı oluşu ve istatistiksel analizler ile birlikte kullanılabilir olması kinematik analiz yönteminin başlıca avantajlarıdır. Ancak, yöntem bu avantajları ile birlikte önemli sınırlamalara da sahiptir. Sadece ön tasarım için uygun olması, kritik süreksizliklerin kesin olarak belirlenmesinin gerekliliği, yenilme yüzeyine ait kohezyonun, dış yüklerin, boşluk suyu basıncının, kayan kütlenin ağırlığının ve dinamik yüklerin dikkate alınmaması bu yöntemin en önemli sınırlamalarıdır. Bu sınırlamalar nedeniyle kinematik analizlerden elde edilen sonuçların ön tasarım için geçerli olacağı, optimum şev tasarımı için bu sonuçların limit denge analizleri veya sayısal analizler ile kontrol edilmesi ve güvenlik katsayılarının belirlenmesi gerekliliği unutulmamalıdır.

İlk olarak Hoek ve Bray (1981) tarafından tanımlanan, Goodman (1989) tarafından geliştirilen ve Wyllie ve Mah (2004) tarafından yeniden düzenlenen kinematik analiz yönteminde, sadece süreksizlik yönelimleri, şev yönelimi ve süreksizlik yüzeylerinin içsel sürtünme açıları dikkate alınarak, düzlemsel, kama ve devrilme türü yenilmeler için duraylılık analizleri yapılmaktadır.

Düzlemsel Yenilme: Kaya şevlerinde sadece bir süreksizlik düzlemine bağlı olarak gelişen bir yenilme türüdür (Şekil 4). Yenilmenin oluşabilmesi için aşağıdaki geometrik koşulların sağlanması gerekmektedir. Bu koşullar;

a) Şevin eğim açısının $\left(\psi_{\mathrm{f}}\right)$ süreksizliğin eğim açısından büyük, süreksizliğin eğim açısının $\left(\psi_{\mathrm{p}}\right)$ ise süreksizliğin içsel sürtünme açısından $\left(\phi_{\mathrm{p}}\right)$ büyük olması,

$\left(\psi_{\mathrm{f}}\right)>\left(\psi_{\mathrm{p}}\right)>\left(\phi_{\mathrm{p}}\right)$

b) Şevin eğim yönü açısı ile süreksizliğin eğim yönü açısı arasındaki farkın $\pm 20^{\circ}$ den büyük olmaması,

c) Kayan kütlenin iki tarafında yenilmeye karşı çok az direnç gösteren yan yüzeylerin bulunması şeklinde sıralamak mümkündür. 

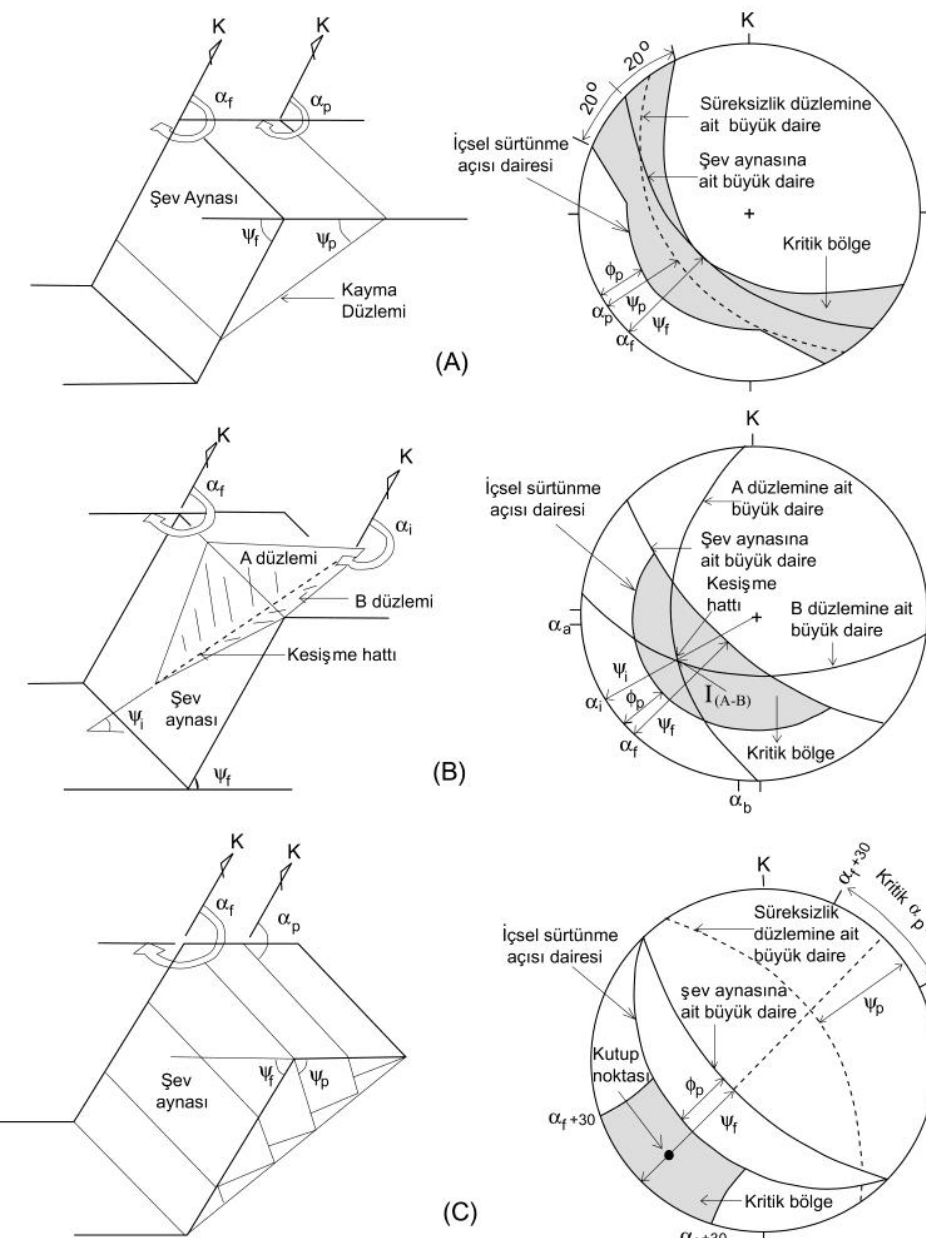

(C)

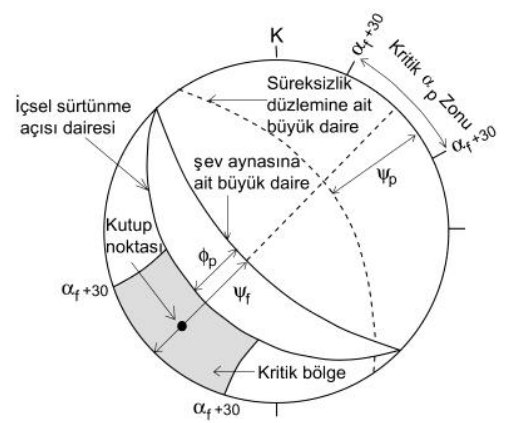

$$
\begin{aligned}
& \alpha_{p}: \text { Süreksizliğin eğim yönü } \\
& \psi_{p}: \text { Süreksizliğin eğimi } \\
& \alpha_{f}: \text { Şevin eğim yönü } \\
& \psi_{f}: \text { Şevin eğimi } \\
& \phi_{p}: \text { Süreksizliğin içsel sürtünme açıS। }
\end{aligned}
$$

$$
\begin{aligned}
& \alpha_{a}: \text { A düzleminin eğim yönü } \\
& \alpha_{b}: \text { düzleminin eğim yönü } \\
& \alpha_{\mathrm{i}}: \text { Kesişme hattının dalım açısı } \\
& \psi_{\mathrm{i}}: \text { Kesişme hattının dalımı }
\end{aligned}
$$

Şekil 4: Kaya şevlerinde düzlemsel $(A)$, kama tipi $(B)$ ve devrilme (C) yenilmelerinin gelişebilmesi için gereken kinematik şartlar (Norrish and Wyllie 1996).

Kama Tipi Yenilme: Şev yüzeyinde kesişen iki süreksizlik düzleminin oluşturduğu kamanın, bu kesişme hattı boyunca kayması şeklinde ortaya çıkmaktadır (Şekil 4). Ancak, kaya kütlesinde kesişen süreksizliklerin varlığı her zaman kama türü duraysızlığa neden olmaz. Duraysızlığın oluşabilmesi için süreksizliklere ait büyük dairelerin kesişim noktasının $\left(\mathrm{I}_{\mathrm{A}-\mathrm{B}}\right)$, stereografik iz düşümde içsel sürtünme açısı dairesi ile şev düzlemine ait büyük daire arasında kalan kritik bölgeye (Şekil 4) düşmesi gerekmektedir. Böylece, kama türü duraysızlık için gerekli olan kesişme noktasının dalım açısının $\left(\psi_{\mathrm{i}}\right)$ şevin eğim açısından $\left(\psi_{\mathrm{f}}\right)$ küçük, süreksizliğin eğim açısından $\left(\psi_{\mathrm{p}}\right)$ büyük olması şartı da sağlanmış olacaktır.

Devrilme Yenilmesi: Bu yenilme türü, şev eğim yönünün tersi yönde eğimli ve yüksek devamlllı̆ga sahip süreksizlikler boyunca oluşabilmektedir (Şekil 4). Devrilme türü duraysızlığın oluşabilmesi için;

a) $\left(90-\psi_{f}\right)+\phi_{p}<\psi_{p}$

b) $\alpha_{\beta}=\left(\alpha_{f}+180\right) \pm 30^{\circ}$

şartlarının sağlanması gerekmektedir. Burada dikkat edilmesi gereken en önemli durum, süreksizliğin eğim yönünün $\left(\alpha_{\beta}\right)$ şevin eğim yönüne $\left(\alpha_{\mathrm{f}}\right)$ zıt yönde olması gerektiğidir.

Bu çalışmada Gümüşhane Granitoyidi’nde kesilmiş olan kaya şevlerinde eklemlere bağlı olarak meydana gelebilecek duraysızlıkları ve güvenli şev yönelimlerini belirlemek için kinematik analizler yapılmıştır. Yapılan analizlerde kullanılan parametreler Tablo 4'de, kinematik analizlere ait sonuçlar ise Tablo 5'de verilmiştir. 
Tablo 4: Kinematik analizlerde kullanılan parametreler

\begin{tabular}{|l|c|c|c|c|c|c|c|c|}
\hline \multirow{2}{*}{ Parametreler } & \multicolumn{7}{|c|}{ Şevler } \\
\cline { 2 - 9 } & $\mathbf{1}$ & $\mathbf{2}$ & $\mathbf{3}$ & $\mathbf{4}$ & $\mathbf{5}$ & $\mathbf{6}$ & $\mathbf{7}$ \\
\hline \multicolumn{2}{|c|}{ İçsel Sürtünme Açıs1 $\left(\phi^{\circ}\right)$} & 49 & 49 & 45 & 59 & 44 & 39 & 47 \\
\hline \multicolumn{2}{|c|}{ Şev Yönelimleri } & $208 / 48$ & $352 / 71$ & $165 / 72$ & $160 / 60$ & $170 / 66$ & $130 / 64$ & $175 / 68$ \\
\hline \multirow{3}{*}{$\begin{array}{l}\text { Eklem } \\
\text { Yönelimleri }\end{array}$} & 1 & $144 / 66$ & $225 / 54$ & $265 / 45$ & $132 / 60$ & $220 / 75$ & $144 / 46$ & $263 / 54$ \\
\cline { 2 - 9 } & 2 & $116 / 68$ & $158 / 48$ & $184 / 77$ & $170 / 56$ & $162 / 64$ & $79 / 48$ & $229 / 82$ \\
\cline { 2 - 9 } & 3 & $160 / 28$ & $38 / 65$ & $255 / 64$ & $178 / 82$ & $247 / 53$ & $67 / 33$ & $41 / 87$ \\
\cline { 2 - 9 } & 4 & $277 / 85$ & - & $134 / 47$ & $214 / 72$ & - & $78 / 82$ & $314 / 81$ \\
\hline
\end{tabular}

Tablo 5: Kinematik analizler sonucunda şevlerde meydana gelebilecek olası duraysızlıklar ve güvenli şev yönelimleri

\begin{tabular}{|c|c|c|c|c|}
\hline \multirow[b]{2}{*}{ Şevler } & \multicolumn{3}{|c|}{ Duraysızlık Tipi } & \multirow[b]{2}{*}{$\begin{array}{l}\text { Güvenli şev } \\
\text { yönelimleri }\end{array}$} \\
\hline & $\begin{array}{l}\text { Düzlemsel } \\
\text { Yenilme }\end{array}$ & $\begin{array}{c}\text { Kama Tipi } \\
\text { Yenilme }\end{array}$ & $\begin{array}{l}\text { Devrilme } \\
\text { Yenilmesi }\end{array}$ & \\
\hline 1 & Duraylı & Durayl1 & Duraylı & $208 / 48$ \\
\hline 2 & Durayli & Durayli & Durayli & $352 / 71$ \\
\hline 3 & Duraylı & Duraylı & Duraylı & $165 / 72$ \\
\hline 4 & Duraylı & Duraylı & Duraylı & $160 / 60$ \\
\hline 5 & $\begin{array}{l}2 \text { nolu ekleme bağlı } \\
\text { düzlemsel yenilme }\end{array}$ & $\begin{array}{c}\text { (1-2) ve (2-3) nolu } \\
\text { eklem çiftlerine } \\
\text { bağlı kama tipi } \\
\text { yenilme }\end{array}$ & Duraylı & $170 / 59$ \\
\hline 6 & $\begin{array}{l}1 \text { nolu ekleme bağl1 } \\
\text { düzlemsel yenilme }\end{array}$ & $\begin{array}{c}\text { (1-2) ve (1-4) nolu } \\
\text { eklem çiftlerine } \\
\text { bağl1 kama tipi } \\
\text { yenilme }\end{array}$ & Duraylı & $130 / 43$ \\
\hline 7 & Duraylı & $\begin{array}{l}\text { (1-4) nolu eklem } \\
\text { çiftine bağlı kama } \\
\text { tipi yenilme }\end{array}$ & Duraylı & $175 / 67$ \\
\hline
\end{tabular}

Kaya şevleri için yapılan kinematik analiz sonuçlarına göre (1), (2), (3) ve (4) nolu kaya şevlerinde eklemlere bağlı olarak herhangi bir yenilme olasılığının olmadığı görülmektedir. Ancak, (5) nolu kaya şevinde (2) nolu eklem setine bağlı olarak düzlemsel, (1-2) ve (2-3) nolu eklem çiftlerine bağlı kama tipi yenilme olasılığı vardır. Kinematik analiz sonuçları (6) nolu kaya şevinde (1) nolu eklem setine bağlı olarak düzlemsel, (1-2) ve (1-4) nolu eklem çiftlerine bağlı kama tipi yenilme, (7) nolu kaya şevinde ise (1-4) nolu eklem çiftine bağlı olarak kama tipi yenilme olasılığının olduğunu göstermektedir. Bu şevler için devrilme yenilmesi olasıllğı bulunmamaktadır. (5), (6) ve (7) nolu kaya şevleri için olası yenilmeleri ortadan kaldıracak güvenli şev yönelimleri belirlenmiş̧ir (Tablo 5). Güvenli şev yönelimleri belirlenirken, proje özelliği ve topoğrafyanın eğim yönündeki değişikliklere her zaman izin vermemesi ve daha uygulanabilir olması nedeniyle kaya şevlerinin eğim açıları revize edilmiştir.

Kinematik analizler, kaya şevlerinde meydana gelebilecek olası yenilme tipleri hakkında ön bilgi vermesi açısından oldukça pratik bir analiz yöntemi olmasına karşıllık, bu yöntemde yenilme yüzeyine ait kohezyon ve içsel sürtünme açısının, dış yüklerin, boşluk suyu basıncının, kayan kütlenin ağırlığının ve dinamik yüklerin dikkate alınmaması nedeniyle, kinematik analizlerden ortaya çıkan sonuçların güvenirliği, limit denge veya sayısal analizler ile kontrol edilmesi gerekmektedir.

\subsection{Limit Denge Analizleri}

Şevlerin duraylılığının değerlendirilmesinde yaygın bir şekilde kullanılan ve güvenlik katsayısının (F) hesaplanabildiği limit denge analizleri, eğimli bir yüzey üzerindeki bloğun üzerinde etkin olan kaymayı sağlayan ve kaymaya karşı koyan kuvvetlerle dengelendiğini varsayan "limit denge" kavramı temeline dayanmaktadır (Goodman 1995). Bu yöntemlerde, yenilme yüzeyine ait kohezyon ve içsel sürtünme açısııın, dış yüklerin, boşluk suyu basıncının, kayan kütlenin ağırlığının ve dinamik yüklerin dikkate alınması sonucunda elde edilen güvenlik katsayısı (F), şev üzerine etkiyen tüm kuvvetleri kayma yüzeyine dik ve paralel bileşenlerine ayırmak suretiyle hesaplanır. Düzlem aşağı yönde etkiyen kesme kuvvetlerin vektör toplamına kaydıran kuvvetler, toplam normal kuvvetlerin içsel sürtünme açılarının tanjantı ile çarpımının kohezyonla toplamı ise direnen kuvvetler olarak tanımlanır. Kayan bloğun F değeri ise direnen kuvvetlerin kaydıran kuvvetlere oranıdır (Wyllie and Mah 2004). Elde edilen F değerleri, şevin yüksekliği ve yönelimi, 
basamak genişliği gibi tasarım kriterlerinin gözden geçirilerek optimum şev tasarımının yapılmasına imkan sağlamaktadır.

Bu çalışmada, kinematik analizler sonucunda (5), (6) ve (7) nolu kaya şevlerinde meydana gelmesi olası düzlemsel ve kama tipi yenilmeler için Planar Failure Analysis v2.0 ve Wedge Failure Analysis v2.0 (Kroeger 1999a, b) bilgisayar programları kullanılarak iki boyutlu limit denge analizleri yapılmış ve güvenlik katsayıları belirlenmiştir. Düzlemsel ve kama tipi yenilmelerin limit denge analizlerinde kullanılan girdi parametreleri ve analizler sonucunda elde edilen $\mathrm{F}$ değerleri Tablo 6'da verilmiştir. Analizlerde, eklemlerin makaslama dayanımlarının sadece sürtünmeden kaynaklanacağı ve kohezyonun olmadığı varsayılmıştır.

Tablo 6: Limit denge analizlerinde kullanılan girdi parametreleri ve F değerleri

\begin{tabular}{|c|c|c|c|c|c|c|c|c|}
\hline $\begin{array}{l}\text { Şev } \\
\text { No }\end{array}$ & $\underset{\text { tipi }}{\text { Duraysızlık }}$ & $\begin{array}{c}\text { Şev } \\
\text { Yüksekliği } \\
\text { (m) }\end{array}$ & $\begin{array}{c}\text { Şev } \\
\text { yönelimi }\end{array}$ & $\begin{array}{c}\text { Şevin üst } \\
\text { yüzeyinin } \\
\text { eğim } \\
\text { açısı }\end{array}$ & $\begin{array}{c}\text { Eklem } \\
\text { yönelimi }\end{array}$ & $\begin{array}{l}\text { Eklemlerin } \\
\text { içsel } \\
\text { sürtünme } \\
\text { açısı }\end{array}$ & $\begin{array}{c}\text { Kaya } \\
\text { malzemesinin } \\
\text { birim hacim } \\
\text { ăgırlığı } \\
\left(\mathbf{k N} / \mathbf{m}^{3}\right) \\
\end{array}$ & $\begin{array}{l}\text { Güvenlik } \\
\text { Katsayısı } \\
\text { (F) }\end{array}$ \\
\hline 5 & Düzlemsel & 15 & $170 / 66$ & 5 & $162 / 64$ & 44 & 25.30 & 0.471 \\
\hline \multirow{2}{*}{5} & \multirow{2}{*}{$\begin{array}{c}\text { Kama } \\
(1-2)\end{array}$} & \multirow{2}{*}{15} & \multirow{2}{*}{$170 / 66$} & \multirow{2}{*}{5} & $220 / 75$ & \multirow{2}{*}{44} & \multirow{2}{*}{25.30} & \multirow{2}{*}{0.476} \\
\hline & & & & & $162 / 64$ & & & \\
\hline \multirow{2}{*}{5} & \multirow{2}{*}{$\begin{array}{c}\text { Kama } \\
(2-3)\end{array}$} & \multirow{2}{*}{15} & \multirow{2}{*}{$170 / 66$} & \multirow{2}{*}{5} & $162 / 64$ & \multirow{2}{*}{44} & \multirow{2}{*}{25.30} & \multirow{2}{*}{0.998} \\
\hline & & & & & $247 / 53$ & & & \\
\hline 6 & Düzlemsel & 22 & $130 / 64$ & 5 & $144 / 46$ & 39 & 24.50 & 0.782 \\
\hline \multirow{2}{*}{6} & \multirow{2}{*}{$\begin{array}{c}\text { Kama } \\
(1-2)\end{array}$} & \multirow{2}{*}{22} & \multirow{2}{*}{$130 / 64$} & \multirow{2}{*}{5} & $144 / 46$ & \multirow{2}{*}{39} & \multirow{2}{*}{24.50} & \multirow{2}{*}{0.975} \\
\hline & & & & & $79 / 48$ & & & \\
\hline \multirow{2}{*}{6} & \multirow{2}{*}{$\begin{array}{c}\text { Kama } \\
(1-4)\end{array}$} & \multirow{2}{*}{22} & \multirow{2}{*}{$130 / 64$} & \multirow{2}{*}{5} & $144 / 46$ & \multirow{2}{*}{39} & \multirow{2}{*}{24.50} & \multirow{2}{*}{0.783} \\
\hline & & & & & $78 / 82$ & & & \\
\hline \multirow{2}{*}{7} & \multirow{2}{*}{$\begin{array}{c}\text { Kama } \\
(1-4)\end{array}$} & \multirow{2}{*}{15} & \multirow{2}{*}{$175 / 68$} & \multirow{2}{*}{5} & $263 / 54$ & \multirow{2}{*}{47} & 2160 & \\
\hline & & & & & $314 / 81$ & & 24.00 & $1.4 / 8$ \\
\hline
\end{tabular}

Kinematik analiz sonuçlarından (5) ve (6) nolu kaya şevlerinde gerçekleşmesi olası düzlemsel ve kama tipi yenilmelerin limit denge analizlerine göre güvenlik katsayılarının 1 den küçük $(\mathrm{F}<1)$ olduğu ve bu şevlerde düzlemsel ve kama tipi duraysızlıkların meydana geleceği görülmektedir. (7) nolu kaya şevi için kinematik analiz sonuçları kama tipi yenilme olasılığı vermesine karşın, limit denge analiz sonucu şevin F değerinin 1'den büyük (F=1.478) olduğunu ve herhangi bir duraysızlığın söz konusu olmadığını göstermektedir.

Limit denge analizlerinin ikinci aşamasında, kinematik olarak belirlenen olası yenilme tiplerini ortadan kaldırmak için ve Tablo 5'de verilen güvenli şev yönelimleri kullanılarak yeniden analizler yapılmış ve önerilen şev yönelimlerinin duraylı olup olmadıkları incelenmiştir. Yapılan analiz sonuçlarına göre, bu çalışmada önerilen eğim açıları dikkate alınarak (5) ve (6) nolu kaya şevlerinin yatıklaştırılması durumunda, tüm duraysızlıkların ortadan kalktığ belirlenmiştir.

\section{Sonuçlar ve Öneriler}

Bağlarbaş1-Tekke (Gümüşhane) karayolunda Gümüşhane Granitoyidi içerisinde kesilmiş olan yedi adet kaya şevinin duraylılıklarının incelendiği bu çalışma sonucunda;

1. İncelenen kaya şevlerinde Gümüşhane Granitoyidi'nin 4 ana eklem seti ve gelişigüzel yönelime sahip eklem setleri içermektedir, bu eklemler yakın ara uzaklıklı, orta derecede geniş, çok düşük devamlı, pürüzlü, genellikle 2-5 mm aralığında kil dolgulu orta-fazla bozunmuş ve kuru özelliktedir.

2. Yapılan kinematik analizler, (1), (2), (3) ve (4) nolu kaya şevlerinde eklemlere bağlı olarak herhangi bir yenilme olasılığının olmadığını göstermektedir.

3. Kinematik analiz sonuçlarına göre; (5) nolu kaya şevinde (2) nolu eklem setine bağlı olarak düzlemsel, (1-2) ve (2-3) nolu eklem çiftlerine bağlı kama tipi yenilme; (6) nolu kaya şevinde (1) nolu eklem setine bağlı olarak düzlemsel, (1-2) ve (1-4) nolu eklem çiftlerine bağlı kama tipi yenilme; (7) nolu kaya şevinde ise (1-4) nolu eklem çiftine bağlı olarak kama tipi yenilme olasılığı mevcuttur. Analiz sonuçları, kaya şevlerinde devrilme yenilmesinin gerçekleşme olasılığının olmadığını göstermektedir.

4. Kinematik olarak düzlemsel ve kama tipi yenilme olasılığının bulunduğu 5, 6 ve 7 nolu kaya şevleri için yapılan limit denge analizlerinde, (5) nolu şevdeki olası düzlemsel ve kama tipi yenilmelere ait güvenlik katsayıları (F) sirasıyla 0.471, 0.476 ve 0.998 olarak belirlenmiştir. Bu değerler (5) nolu kaya şevinde düzlemsel ve kama tipi duraysızlıkların oluşacağını ve şevin duraylı hale getirilebilmesi için şev açısının $59^{\circ}$ ye düşürülmesi gerektiğini 
göstermektedir. Benzer şekilde, (6) nolu kaya şevinde olası düzlemsel ve kama tipi yenilmelere ait güvenlik katsayıları (F) sırasıyla 0.782, 0.975 ve 0.783 olarak belirlenmiştir. Bu kaya şevi için de düzlemsel ve kama tipi yenilmeler söz konusudur ve şevin eğim açısı $43^{\circ}$ ye düşürülmesi durumunda bu duraysızlıklar ortadan kalkacaktır.

5. (7) nolu kaya şevi için yapılan limit denge analizleri, kinematik olarak kama tipi yenilme olasılığı olmasına karşın, F değerinin 1.478 olduğu ve yenilmenin oluşmayacağını, şevin duraylı olduğunu göstermektedir.

6. Bu çalışmadan elde edilen veriler, kaya şevlerinin duraylılığının incelenmesinde kinematik analiz gibi olasılık analizlerinin optimum şev tasarımı için yeterli olamayacağını, kinematik analizlerden elde edilen sonuçların, limit denge veya sayısal duraylılık analizleri ile mutlaka kontrol edilmesi gerekliliğini göstermesi açısından önem taşımaktadır.

\section{Kaynaklar}

Alemdag S., Akgun A., Kaya A., Gokceoglu C., (2014), A large and rapid planar failure: Causes, mechanism and consequences (Mordut, Gumushane, Turkey), Arabian Journal of Geosciences, 7(3), 205-1221.

Attewell P.B., Farmer, I.W., (1976), Principles of engineering geology, Chapman and Hall, London.

Barton M.R., (1973), Review of a new shear strength criterion for rock joints, Engineering Geology, 7, 287-332.

Barton M.R., Choubey V., (1977), The shear strenght of rock and rock joints, International Journal of Rock Mechanics and Minning Sciences and Geomechanics Abstracts, 13, 255-279.

CANMET, (1977), Laboratory tests for design parametres. In Pit Slope Manual of CANMET, Supplement 3-2, Canada Centre for Mineral and Energy Technology Report 77-26.

Fookes P.G., Denness B., (1969), Observational studies on fissure patterns in Cretaceous sediments of southeast England, Geotechnique, 19 (4), 453-77.

Gokceoglu C., Sonmez H., Ercanoglu M., (2000), Discontinuity controlled probabilistic slope failure risk maps of the Altındağ (settlement) region in Turkey, Engineering Geology, 55, 277-296.

Goodman R.E., (1989), Introduction to rock mechanics, 2nd edition, Wiley, New York.

Goodman R, E., (1995), Block theory and its application, Geotechnique, 45(39), 383-422.

Gurocak Z., Alemdag S., Zaman M., (2008), Rock slope stability and excavatability assessment of rocks at the Kapikaya Dam site, Eastern Turkey, Engineering Geology, 96(1-2), 17-27.

Hoek E., Bray J., (1977), Rock slope engineering, 1st edn, IMM, London.

Hoek E., Bray J.W., (1981), Rock slope engineering, Third Edition, The Institution of Mining and Metallurgy, London.

ISRM, (1978), Suggested methods for the quantitative description of discontinuities in rock masses, International Rock Mechanics and Mining Science, Geomech. Abstr. 15, 319-368.

ISRM, (2007), The complete isrm suggested methods for rock characterization, testing and monitoring: 1974-2006. Suggested Methods prepared by the Commission on Testing Methods, ISRM, R. Ulusay and J.A. Hudson (Ed.), Kozan Ofset, Ankara, 628s.

Jenning J.E., (1970), A mathematical theory for the calculation of the stability of open cast mines, Proc. Symp. On Planning Open Pit Mines, Cape Town, Balkema, ss.87-112.

Kentli B., Topal T., (2004), Assesment of rock slope stability for a segment of the Ankara-Pozanti motorway Turkey, Engineering Geology, 74(1-2), 73-90.

Ketin İ., (1966), Tectonic units of Anatolia. Bull. Mineral Research and Exploration Institute of Turkey, 66, 22-34.

Kroeger E.B., (1999a), Planar Failure Analysis version 2.0.

Kroeger E.B., (1999b), Wedge Failure Analysis version 2.0.

Özkirișçi Oktay C., (2014), Bağlarbașı-Tekke (Gümüşhane) arasındaki kesilmiş kaya șevlerinin duraylılı̆̆ının incelenmesi, Yüksek Lisans Tezi, Gümüşhane Üniversitesi, Fen Bilimleri Enstitüsü, Gümüşhane.

Piteau D.R., (1970), Geological factors significant to the stability of slopes cut in rock, Proc. of The Symp. on Planning Open Pit Mines, South African Institute of Mining and Metallurgy., Johannesburg, ss.33-53.

Priest S.D., Hudson J.A., (1981), Estimation of discontinuity spacing and trace lengthusing scanline surveys, International Journal of Rock Mechanics and Mining Sciences and Geomechanics Abstracts, 18(3), 183-197.

Rocscience, (2002), Dips v5.1 Graphical and statistical analysis of orientation data, Rocscience Inc., Toronto, Ontario.

Rocscience, (2004), User's guide of rocdata: Strength analysis of rock and soil masses using the generalized Hoek-Brown, MohrCoulomb, Barton-Bandis and Power Curve failure criteria, version 3.0 ed. Rocscience Inc., Toronto, Ontario,

Tudes S., Ceryan S., Bulut F., (2012), Geoenvironmental evaluation for planning: an example from Gumushane City, Bull. Eng. Geol. Environ., 71(4), 679-690.

Wyllie D.C., Mah C.W., (2004), Rock slope engineering civil and mining, Spon Press, Taylor and Francis e-library.

Y1lmaz I., Marschalko M., Yıldırım M., Dereli E., Bednarik M., (2012), GIS-based kinematic slope instability and slope mass rating (SMR) maps: application to a railway route in Sivas (Turkey), Bull. Eng. Geol. Environ., 71(2), 351-357.

Yılmaz Y., (1972), Geology of the Gümüşhane Granitoyidi (petrography), İstanbul Üniversitesi Fen Fakültesi Seri B, 157-172.

Yoon W.S., Jeong U.J., Kim J.H., (2002), Kinematic analysis for sliding failure of multi-faced rock slopes, Engineering Geology, 67(1-2), 51-61. 